\title{
Awareness assessment for parents of children with congenital heart diseases regarding fetal echocardiography
}

\author{
Shaimaa Rakha ${ }^{\odot}$ \\ Department of Pediatric Cardiology, Mansoura University Faculty of Medicine, El Gomhouria St, Mansoura, Egypt.
}

\begin{abstract}
Background and objectives. The high recurrence rate of congenital heart disease (CHD) in siblings was the rationale for recommending fetal echocardiography. However, in a developing country like Egypt, there are limited fetal echocardiographic examinations under this category. The study was conducted to assess knowledge about fetal echocardiography amongst parents of children with CHD.
\end{abstract}

Method. A questionnaire survey was conducted in a tertiary pediatric hospital from June to December 2018. The study included parents having children with CHD follow up in the outpatient clinic or admitted in the pediatric cardiology ward. The questionnaire included demographic data of parents regarding sex, age, education, and residence. It also includes a detailed inquiry about parents' knowledge regarding the availability, safety, and value of fetal echocardiography.

Results. Participants were 200 parents, mostly mothers 159 (79.5\%). The median age of parents included in the study was 33.5 (29-40) years. Regarding awareness, 134 (67\%) did not know any prenatal diagnostic investigation for CHD, 46 (23\%) knew fetal echocardiography, and 20 (10\%) named other tools. Nevertheless, $34 \%$ of parents thought they would need fetal echocardiography in a subsequent pregnancy. Although 178 $(89 \%)$ of parents thought it might be a safe investigation, 33\% did not think it will have additional benefits over postnatal echocardiography. The age of the patient and age of the participating parent were the only statistically significant predictors for parents knowledge on fetal echocardiography existence with $p=0.008,95 \% \mathrm{CI}=1.039$ 1.282 and $\mathrm{p}=0.015,95 \% \mathrm{CI}=0.864-0.984$, respectively.

Conclusion. Parents of children with CHD have significant knowledge gaps regarding Fetal Echocardiography. Our findings suggest that the current parent counseling is inadequate and needs further focus, especially in developing countries, to promote parents' understanding of the prenatal cardiac diagnosis. Data on fetal echocardiography should be clarified at the initial diagnosis of pediatric CHD.

Key words: awareness, parents, congenital heart disease, fetal echocardiography.

Congenital heart diseases (CHD) are the most prevalent anomaly with an incidence of 8 per 1000 live births. ${ }^{1,2}$ Fetal echocardiography is considered the standard imaging technique used for the diagnosis and assessment of CHDs in prenatal life with high sensitivity and specificity., ${ }^{3,4}$ It also provides details about the anatomy and functions of the fetal heart. Commonly, it is performed between 18

Shaimaa Rakha

drshimaarhaka@mans.edu.eg

Received 23rd July 2019, revised 26th September 2019, accepted 16th December 2019. weeks and 22 weeks of gestational age. ${ }^{5}$ Fetal echocardiography is considered essential for the identification of CHDs, timely interventions, and counseling of parents. ${ }^{6}$ Furthermore, accurate diagnosis of fetal heart lesions offers several benefits, including improvements in outcomes of critical neonatal cardiac anomalies.?

The recurrence risk of cardiac anomalies in siblings with unaffected parents is $2-6 \% .^{8-10}$ The risk for recurrence is higher if more than one sibling is affected. ${ }^{11,12}$ Besides, some lesions might have more tendency for recurrence with risk up to $8 \%$ such as hypoplastic left heart syndrome (HLHS). ${ }^{13,14}$ The concordance for most lesions 
were found to be $<50 \%$, while exact concordance for CHDs may be around 20-35\%. ${ }^{15,16}$ Hence, fetal echocardiography is indicated with family history of CHD, especially in a sibling. According to the American Heart Association scientific statement on fetal cardiology, it is recommended with a level of evidence I/B. ${ }^{16}$ However, fetal echocardiographic examinations under this category of indications are still limited, particularly in a developing country like Egypt. The counseling for the parents of children with CHD about antenatal diagnosis and its benefits is considered a fundamental step in the management of pediatric CHD. Therefore, the current study was conducted to assess the knowledge gaps about fetal echocardiography amongst parents of children with CHD to determine the success in the counseling process of parents regarding that point.

\section{Material and Methods}

A questionnaire survey was conducted from June to December 2018 in a tertiary pediatric hospital, Mansoura University Children Hospital, Egypt. The study was approved by the institutional review board of Mansoura University, Faculty of medicine with number of R.18.11.334 on $11 / 2018$. The included participants in the study were the parents of children with CHD followed up in the pediatric cardiology outpatient clinic or admitted in the pediatric cardiology ward. All enrolled parents were informed about the study and written consent was obtained. Parents of pediatric patients with acquired heart diseases or arrhythmia were excluded from the data analysis. The patients who were visiting the hospital as newly diagnosed cases were not included. Patients accompanied to the hospital with non-legal guardians like grandparents and other relatives were excluded.

Before we began the questionnaire, demographic and clinical data of the patients were collected from their hospital records such as age, gender, primary cardiac lesion, and associated syndromes. Parents were approached in the waiting room of the outpatient area or the patient's room on the inpatient floors. The questionnaire was conducted with face to face interview with the parents at the end of the outpatient visit or during the hospital stay with further clarification using phone if necessary. A pilot study was carried out with parents to ensure that the questions were easily understood. The survey included questions about parents' demographics, such as sex, age, employment, education, and residence. We asked the parents about having a child or pregnancy after the currently affected and if fetal echocardiography was performed. Moreover, it included a detailed inquiry about parents' awareness regarding knowledge of availability, safety, appropriate time, and value of fetal echocardiography. The parent questionnaire is demonstrated in Table I.

Statistical analysis was performed using the Statistical Package for the Social Sciences (SPSS), version 25 (SPSS, Inc, an IBM Company, Chicago, IL, USA). Data are expressed as frequency and percentage or median and interquartile range according to the variable. Logistic regression analysis was used to identify significant determinants of awareness about fetal echocardiography. A probability value of $\mathrm{p}<0.05$ was considered significant. Microsoft Office Excel 2013 (Microsoft, Inc., Redmond, WA, USA) was used for formulating tables and graphs.

\section{Results}

A questionnaire survey was conducted in a tertiary pediatric hospital from June to December 2018. During six months, 200 parents of patients with CHD accepted to participate in our study. The demographic information for the study cohort is enlisted in Table II. The median age of the child with CHD was 5 (1.5-11) months and most frequently being females 106 (53.0\%). Most of the patients had acyanotic CHD 164 $(82 \%)$, and136 (68\%) of the cases did not require catheter or surgical intervention. Also, most of the patients were non-syndromic 180 (90\%), with Down syndrome, the most frequently associated syndrome found in $11(5.5 \%)$. 
Table I. Parents questionnaire used in the study.

- Age of the participating parent

- The participating parent

- Father

- Mother

- Parent Education

- None schooled

- Middle school

- High school or equivalent education

- University graduate

- Postgraduate education

- Parent Residence

- Urban

- Rural

- Parent Occupation

- Employed

- Non- Employed

- Do you know any investigation used to detect heart disease antenatally?

- No

- Yes (mention?)

- Did you hear about fetal echocardiography?

- No

- Yes (mention the source?)

- Did you have a pregnancy after the affected child?

- No

- Yes (did you have fetal Echo? Any detected CHD?)

- Do you think in the subsequent pregnancy you (your partner) will need a fetal Echocardiography?

- No

- Yes

- When do you think the best time during pregnancy is to have a fetal Echocardiography?

- Do you think the fetal Echocardiography is risky for the fetus and Mother?

- No

- Yes

- Unknown

- Do you think the antenatal diagnosis of congenital heart diseases is beneficial?

- Do you think the fetal Echocardiography is risky for the fetus and Mother?

- No

- Yes (how)

On analyzing the parents' demographics, the median age of participating parents at the time of the survey was 33.5 (29-40) years. Mothers were more commonly enrolled (162 mothers versus 38 fathers). Regarding education, the majority of parents were high school graduates $71(35.5 \%)$ followed by middle-schooled parents 56 (28\%). Furthermore, most of the study subjects were residents in rural areas (145 $(72.5 \%))$.
Diagnoses of the primary CHD in the patients whose parents were included in the study are demonstrated in Table III. The most frequent cardiac lesion in the children was Ventricular Seotal Defect (VSD) followed by Pulmonary stenosis (PS); 64 (32\%) and 33(16.5\%), respectively.

Table IV demonstrates the parents' extent of awareness regarding prenatal cardiac diagnosis. 
Table II. Baseline characteristics of the patients and their parents.

\begin{tabular}{|c|c|c|}
\hline Variable & \multicolumn{2}{|c|}{$\mathrm{N}(\%)$ or median (IQR) } \\
\hline Age of the patient in Months & \multicolumn{2}{|c|}{$5(1.5-11)$} \\
\hline \multirow[t]{2}{*}{ Sex of patients } & Male & $94(47.0 \%)$ \\
\hline & Female & $106(53.0 \%)$ \\
\hline \multirow[t]{2}{*}{ Patient CHD category } & Cyanotic & $36(18 \%)$ \\
\hline & Acyanotic & $164(82 \%)$ \\
\hline \multirow[t]{3}{*}{ Patient with surgical or catheter intervention } & None & $136(68 \%)$ \\
\hline & Surgery & $34(17 \%)$ \\
\hline & Catheter intervention & $30(15 \%)$ \\
\hline \multirow[t]{7}{*}{ Patient with a confirmed syndrome } & Non syndromic & $180(90 \%)$ \\
\hline & Down syndrome & $11(5.5 \%)$ \\
\hline & Noonan syndrome & $3(1.5 \%)$ \\
\hline & Elis Van Creveled syndrome & $2(1 \%)$ \\
\hline & Alagille syndrome & $2(1 \%)$ \\
\hline & Williams syndrome & $1(0.5 \%)$ \\
\hline & LEOPARD syndrome & $1(0.5 \%)$ \\
\hline Age of the participating parent in years & \multicolumn{2}{|c|}{$33.5(29-40)$} \\
\hline \multirow[t]{2}{*}{ The parent giving the questionnaire } & Mother & $162(81 \%)$ \\
\hline & Father & $38(19 \%)$ \\
\hline \multirow[t]{5}{*}{ Education } & Non-schooled & $35(17.5 \%)$ \\
\hline & Middle schooled & $56(28 \%)$ \\
\hline & High schooled & $71(35.5 \%)$ \\
\hline & University graduate & $36(18 \%)$ \\
\hline & Postgraduate education & $2(1 \%)$ \\
\hline \multirow[t]{2}{*}{ Residence } & Urban & $56(28 \%)$ \\
\hline & Rural & $145(72 \%)$ \\
\hline \multirow[t]{2}{*}{ Occupation } & Housewife or unemployed & $146(73 \%)$ \\
\hline & Employed & $54(27 \%)$ \\
\hline
\end{tabular}

CHD: congenital heart disease, IQR: interquartile range, N: number of cases.

On asking the parents about the availability of a diagnostic investigatory tool for antenatal diagnosis of cardiac disorders, 66 (33\%) of parents confirmed that information but only $46(23 \%)$ knew fetal echocardiography while 20 $(10 \%)$ gave other answers like the conventional prenatal ultrasound, 3D, 4D ultrasound and others did not name the tool as shown in Figure 1. Regarding the information source, $33(17.5 \%)$ were from pediatric cardiologist counseling, followed by family and friends 9 (4.5\%) and obstetrician 7 (3.5\%). The other sources included general pediatrician, other patients' parents, the internet, a doctor relative, and other maternal treating physicians like Diabetes specialist for a diabetic mother. (Fig. 2). A sibling was born after the currently affected child in 45 (22.5\%) of the families and 8/45 had CHD as well. As a result, the recurrence rate of CHD in our cohort is $17.77 \%$. Out of the 45 subsequent siblings or pregnancies, only $12(26.67 \%)$ received a fetal echocardiography.

The appropriate timing for fetal echocardiography was not known in 172 (86\%), whereas $14(7 \%)$ thought it is the 4 th or the 5 th month of gestation. Moreover, 178 (89\%) of the parents thought it would be safe to have fetal echocardiography while $8(4 \%)$ thought it might be risky to the fetus. 
Table III. Diagnosis of the primary CHD in the patients whose parents participated in the study.

\begin{tabular}{lcc}
\hline CHD type & N & \% \\
\hline Atrial septal defect & 24 & 12 \\
Ventricular septal defect & 64 & 32 \\
Patent ductus arteriosus & 15 & 7.5 \\
Atrioventricular septal defect (complete or partial) & 5 \\
Pulmonary stenosis & 10 & 16.5 \\
Aortic stenosis & 33 & 4.5 \\
Aortic coarctation & 9 & 2 \\
Tetralogy of Fallot & 4 & 6 \\
Double outlet right ventricle & 12 & 5.5 \\
Transposition of great arteries & 11 & 2 \\
Double inlet left ventricle & 4 & 0.5 \\
Pulmonary atresia/intact interventricular septum & 1 & 1 \\
Tricuspid atresia & 2 & 0.5 \\
Vascular ring & 1 & 2 \\
Congenital mitral regurgitation & 1 & 0.5 \\
Heterotaxy & 4 & 100 \\
Congenitally corrected transposition of great arteries & 1 & 0.5 \\
Truncus arteriosus & 1 & 0.5 \\
Anomalous pulmonary venous return & 1 &
\end{tabular}

CHD: congenital heart disease, $\mathrm{N}$ : number of cases.

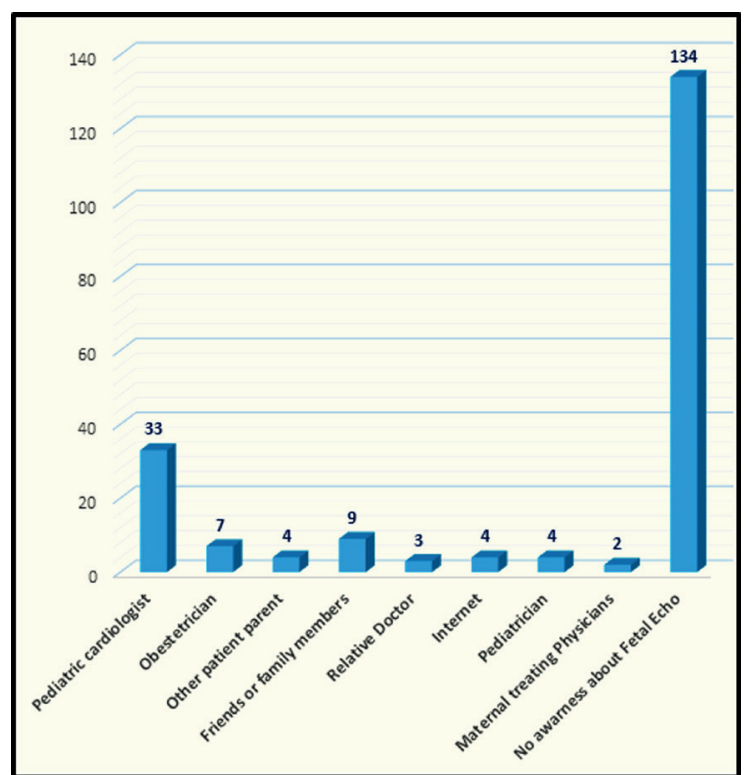

Fig. 1. The sources of parents' awareness of fetal cardiac diseases, diagnostic investigatory tool.

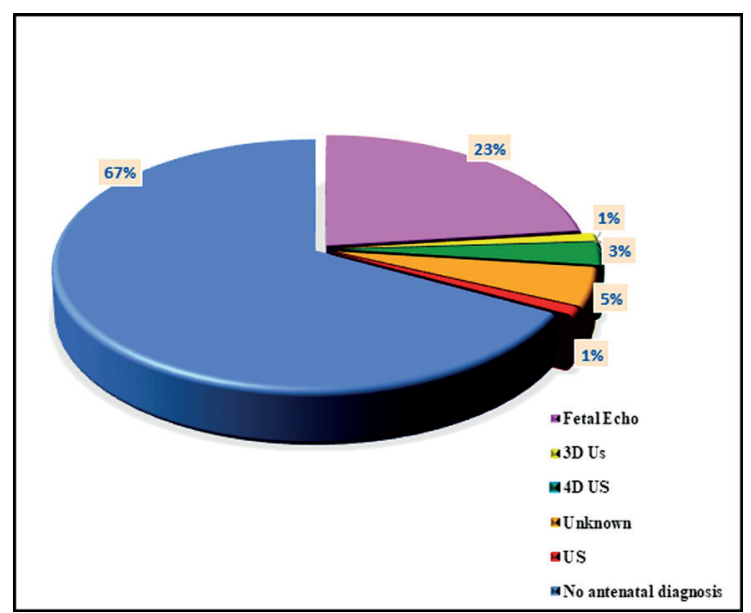

Fig. 2. Pie Chart showing the antenatal cardiac diagnostic investigations as mentioned by parents in percentages. 
Table IV. Data demonstrating the parents' extent of awareness about prenatal cardiac diagnosis.

\begin{tabular}{|c|c|c|}
\hline Parameter & Answer & $\mathrm{N}(\%)$ \\
\hline \multirow[t]{2}{*}{ Investigations to diagnose fetal cardiac diseases } & Yes & $66(33 \%)$ \\
\hline & No & $134(67 \%)$ \\
\hline \multirow[t]{3}{*}{ A child or pregnancy after the patient } & Yes(diagnosed CHD) & $8(16 \%)$ \\
\hline & Yes (no CHD) & $37(18.5 \%)$ \\
\hline & No & $155(77.5 \%)$ \\
\hline \multirow[t]{2}{*}{ Fetal echo in the subsequent sibling } & Yes & $12 / 45$ \\
\hline & No & $33 / 45$ \\
\hline \multirow[t]{3}{*}{ Does fetal echocardiography have risks for mother or fetus? } & Yes & $8(4 \%)$ \\
\hline & No & $178(89 \%)$ \\
\hline & Unknown & $14(7 \%)$ \\
\hline \multirow[t]{6}{*}{ The recommended month of gestation for fetal echocardiography } & 3rd gestation month & $11(5.5 \%)$ \\
\hline & 4th gestation month & $4(2 \%)$ \\
\hline & 5 th gestation month & $10(5 \%)$ \\
\hline & 6th gestation month & $1(0.5 \%)$ \\
\hline & 7th gestation month & $2(1 \%)$ \\
\hline & Unknown & $172(86 \%)$ \\
\hline \multirow[t]{3}{*}{ Value of antenatal cardiac diagnosis } & Yes & $134(67 \%)$ \\
\hline & No & $64(32 \%)$ \\
\hline & Unknown & $2(1 \%)$ \\
\hline \multirow[t]{2}{*}{ Need of fetal echocardiography in the next pregnancy } & Yes & $121(60.5 \%)$ \\
\hline & No & $79(39.5 \%)$ \\
\hline
\end{tabular}

CHD: congenital heart disease, $\mathrm{N}$ : number of cases.

Table V. Benefits of antenatal CHD diagnosis from parents' perspective.

\begin{tabular}{lll}
\hline Value & $\mathrm{N}$ & $\%$ \\
\hline Early diagnosis & 70 & 35 \\
Antenatal treatment & 17 & 8.5 \\
Prepare for postnatal complication & 21 & 10.5 \\
Exclude fetal cardiac disease & 5 & 2.5 \\
Check on fetal wellbeing & 9 & 4.5 \\
Prepare parents antenatal to accept the problem & 7 & 3.5 \\
Avoid antenatal complications or disease progression & 2 & 1 \\
Find the cause of the disease & 3 & 1.5 \\
\hline Total & 134 & 67 \\
\hline
\end{tabular}

CHD: congenital heart disease, $\mathrm{N}$ : number of cases.

The benefits of antenatal CHD diagnosis, as explained by parents, are shown in Table V. Two-thirds of study participants confirmed that it would be of benefit to diagnose CHD in fetal life. Early diagnosis was confirmed to be of a significant benefit by 70 (35\%) of parents, and $21(10.5 \%)$ added that it would help to prepare for postnatal complications. Only 17 $(8.5 \%)$ thought that antenatal cardiac therapy or intervention is possible.

A logistic regression analysis model was created to detect the correlation between patients or parents' demographic data and knowledge regarding the presence of fetal 
echocardiography as summarized in Table VI. The age of the affected child with CHD and the age of the participating parent were statistically significant independent predictors for parents knowledge of fetal echocardiography with $(\mathrm{p}=0.008$, OR:1.15, 95\%CI:1.039-1.282) and $(\mathrm{p}=$ 0.015, OR:0.92, 95\%CI: 0.864-0.984) respectively. In other words, the knowledge of parents on the presence of fetal echocardiography was more likely with increase in the age of their affected child while that knowledge decrease with the increase in parents' age.

\section{Discussion}

The high recurrence risk of cardiac anomalies in siblings was the rationale behind the mandatory fetal echocardiography in the subsequent pregnancies for families having a child with CHD. ${ }^{16}$ In the current study, we have assessed knowledge of parents with children having CHD regarding prenatal cardiac diagnosis from different domains. Despite recent advances in prenatal cardiac detection, the findings of the present study suggest that parents have essential knowledge gaps either in part or entirely.

In our study, only $23 \%$ of the included parents knew about fetal echocardiography which is considered a much higher percentage than a study from India which found that awareness in the parents of CHD children is only $2 \% .{ }^{17}$ Another domain is the extent of awareness, which is lacking at variable levels. Disappointingly, their knowledge appears to be quite deficient.

Regarding the timing, of 46 parents who knew fetal echocardiography, only 14 could roughly determine the standard appropriate time for conventional prenatal diagnosis (the fourth and, the fifth month of gestation). Unfortunately, parents who had a fetal cardiac diagnosis in previous pregnancy with complex CHD and the unfavorable outcome had the impression that antenatal cardiac assessment is unnecessary.

The significant knowledge gap among parents with CHDs in offsprings regarding prenatal cardiac diagnosis and fetal echocardiography

Table VI. Logistic regression analysis of possible determinants of parents' knowledge about fetal echocardiography.

\begin{tabular}{|c|c|c|c|c|}
\hline \multirow{2}{*}{ Covariates } & \multirow{2}{*}{ P value* } & \multirow{2}{*}{ OR } & \multicolumn{2}{|c|}{ 95\% C.I. } \\
\hline & & & Lower & Upper \\
\hline Age of the patient & 0.008 & 1.154 & 1.039 & 1.282 \\
\hline Cyanotic patient & 0.144 & 2.026 & 0.785 & 5.23 \\
\hline Intervention & 0.706 & & & \\
\hline - No intervention vs surgery & 0.808 & 1.143 & 0.388 & 3.374 \\
\hline - Catheter intervention vs surgery & 0.618 & 0.691 & 0.162 & 2.952 \\
\hline Syndromic child with CHD & 0.643 & 1.36 & 0.37 & 5.001 \\
\hline Parent giving questionnaire (Mother) & 0.1 & 0.364 & 0.109 & 1.216 \\
\hline Age of parent giving questionnaire & 0.015 & 0.922 & 0.864 & 0.984 \\
\hline Employment & 0.263 & 0.529 & 0.174 & 1.611 \\
\hline Education & 0.008 & & & \\
\hline - Non-schooled vs postgraduate & 0.244 & 0.155 & 0.007 & 3.57 \\
\hline - Middle-schooled vs postgraduate & 0.181 & 0.126 & 0.006 & 2.627 \\
\hline - High-schooled vs postgraduate & 0.583 & 0.438 & 0.023 & 8.343 \\
\hline - University graduate vs postgraduate & 0.967 & 0.938 & 0.046 & 19.294 \\
\hline Urban residence & 0.397 & 1.424 & 0.628 & 3.226 \\
\hline
\end{tabular}

CHD: congenital heart disease, CI: confidence interval, OR: odds ratio

${ }^{*} \mathrm{P}$ value is significant if $<0.05$ 
could be attributed to a defect in the counseling process at the initial diagnosis. Currently, most of the developing countries suffer from a mismatch between patients' numbers and qualified medical personnel, thereby limiting the time for familial education. ${ }^{17}$ Furthermore, pediatric cardiologists may not want to provide too much information at the initial diagnosis of CHD due to concern that families might be overwhelmed or shocked resulting in lack of the necessary information delivered in the care of fetal or newborn patients with CHD as suggested by Arya et al. ${ }^{18}$ Besides, the fetal echocardiography cost might be one of the obstacles for women with low socioeconomic status in developing as well as some developed countries. ${ }^{19,20}$

However, to raise parents' awareness about the antenatal diagnosis of CHDs, improvements are required on variable levels. Pediatric cardiologists should be the first category to be addressed. Guidelines about the counseling process for families should include data about fetal echocardiography as a fundamental step in themanagement of neonatal and pediatric CHDs. The data regarding fetal echocardiography should be revisited in the follow up in the pediatric cardiology clinics. Furthermore, the general pediatrician should have the necessary information about the indications and benefits of prenatal cardiac diagnosis as a part of their basic training. Besides, health care professional auditing regarding knowledge of the fetal echocardiography is inevitable. In a study, the referral personnel were found to be responsible for the delayed referral of indicated pregnant cases for fetal echocardiography. ${ }^{21}$

Displaying posters, flyers, and brochures in the pediatric cardiology departments and outpatient clinics could be beneficial as well. In the new era of communication platforms like social media, general population awareness could be improved through medical awareness shows.
This study has a few potential limitations. The used methodology is liable for parents to recall bias in some questions, and the questionnaire has not been previously validated. Moreover, subjects enrolled in the study are a cohort of parents of patients in a single center. Therefore, it might not be entirely representable for that category. Further community based large scale studies might be required to assess public awareness as well regarding prenatal cardiac assessment.

In conclusion, parents of children with CHD have significant knowledge gaps regarding prenatal cardiac diagnosis and fetal echocardiography. Our findings suggest that current parent counseling and education are inadequate and needs to be improved to promote better understanding of availability, timing, safety, and prenatal-neonatal value of fetal echocardiography.

\section{Acknowledgments}

The author thanks Dr. Khaled Nagi, resident of pediatrics, Mansoura University Children Hospital, for helping in the parents' interviews.

\section{REFERENCES}

1. Hoffman J, Kaplan S. The incidence of congenital heart disease. J Am Coll Cardiol 2002; 39: 1890-1900.

2. van der Linde D, Konings EE, Slager MA, et al. Birth prevalence of congenital heart disease worldwide: a systematic review and meta-analysis. J Am Coll Cardiol 2011; 58: 2241-2247.

3. Ozkutlu S, Akça T, Kafali G, Beksaç S. The results of fetal echocardiography in a tertiary center and comparison of low-and high-risk pregnancies for fetal congenital heart defects. Anadolu Kardiyol Derg 2010; 10: 263-269.

4. Clur SA, Van Brussel PM, Ottenkamp J, Bilardo CM. Prenatal diagnosis of cardiac defects: accuracy and benefit. Prenat Diagn 2012; 32: 450-455. 
5. Zhang YF, Zeng XL, Zhao EF, Lu HW. Diagnostic value of fetal echocardiography for congenital heart disease: a systematic review and meta-analysis. Medicine (Baltimore) 2015; 94: e1759.

6. Mirza FG, Bauer ST, Williams IA, Simpson LL. Early echocardiography: ready for prime time. Am J Perinatol 2012; 29: 313-318.

7. Tworetzky W, McElhinney DB, Reddy VM, Brook MM, Hanley FL, Silverman NH. Improved surgical outcome after fetal diagnosis of hypoplastic left heart syndrome. Circulation 2001; 103: 1269-1273.

8. Hoffman JI. Incidence of congenital heart disease: I. postnatal incidence. Pediatr Cardiol 1995; 16: 103113.

9. Burn J, Brennan P, Little J, et al. Recurrence risks in offspring of adults with major heart defects: results from fist cohort of British collaborative study. Lancet 1998; 351: 311-316.

10. Nora JJ, Nora AH. Genetic epidemiology of congenital heart diseases. Prog Med Genet 1983; 5: 91-137.

11. Gill HK, Splitt M, Sharland GK, Simpson JM. Patterns of recurrence of congenital heart disease: an analysis of 6,640 consecutive pregnancies evaluated by detailed fetal echocardiography. J Am Coll Cardiol 2003; 42: 923-929.

12. Fesslova V, Brankovic J, Lalatta F, et al. Recurrence of congenital heart disease in cases with familial risk screened prenatally by echocardiography. J Pregnancy 2011; 2011: 368067.

13. Pierpont ME, Basson CT, Benson DW Jr, et al; American Heart Association Congenital Cardiac Defects Committee, Council on Cardiovascular Disease in the Young. Genetic basis for congenital heart defects: current knowledge: a scientific statement from the American Heart Association Congenital Cardiac Defects Committee, Council on Cardiovascular Disease in the Young: endorsed by the American Academy of Pediatrics. Circulation 2007; 115: 3015-3038.
14. Hinton RB Jr, Martin LJ, Tabangin ME, Mazwi ML, Cripe LH, Benson DW. Hypoplastic left heart syndrome is heritable. J Am Coll Cardiol 2007; 50: 1590-1595.

15. Calcagni G, Digilio MC, Sarkozy A, Dallapiccola B, Marino B. Familial recurrence of congenital heart disease: an overview and review of the literature. Eur J Pediatr 2007; 166: 111-116.

16. Donofrio MT, Moon-Grady AJ, Hornberger LK, et al; American Heart Association Adults With Congenital Heart Disease Joint Committee of the Council on Cardiovascular Disease in the Young and Council on Clinical Cardiology, Council on Cardiovascular Surgery and Anesthesia, and Council on Cardiovascular and Stroke Nursing. Diagnosis and treatment of fetal cardiac disease: a scientific statement from the American Heart Association. Circulation 2014; 129: 2183-2242.

17. Warrier D, Saraf R, Maheshwari S, Suresh P, Shah S. Awareness of fetal echo in Indian scenario. Ann Pediatr Cardiol 2012; 5: 156-159.

18. Arya B, Glickstein JS, Levasseur SM, Williams IA Parents of children with congenital heart disease prefer more information than cardiologists provide. Congenit Heart Dis 2013; 8: 78-85.

19. Peiris V, Singh TP, Tworetzky W, Chong EC, Gauvreau K, Brown DW. Association of socioeconomic position and medical insurance with fetal diagnosis of critical congenital heart disease. Circ Cardiovasc Qual Outcomes 2009; 2: 354-360.

20. Sokołowski L. Attitude towards fetal echocardiography among mothers, who gave birth to newborns with congenital heart defect-the survey research. Prenat Cardio 2013; 3: 16-21.

21. Kanwal A, Sheikh AM, Saher T. Determining the factors causing delayed referral for fetal echocardiography at a tertiary care hospital. J Saudi Heart Assoc 2018; 30: 205-210. 